\title{
Asymmetric reduction of 4-Bromo-Acetophenone using whole cells
}

Joyce Benzaquem Ribeiro ${ }^{1}$, Raquel de Oliveira Lopes ${ }^{{ }^{\star}}$, Luciana Dalla Vechia ${ }^{1}$, Aline de Souza Ramos ${ }^{2,3}$, Selma Gomes Ferreira Leite ${ }^{3}$, Rodrigo Octavio Mendonça Alves de Souza ${ }^{1}$

\author{
${ }^{1}$ Instituto de Química, Universidade Federal do Rio de Janeiro, CT Bloco A, Cidade Universitária, Rio de \\ Janeiro RJ 21949-909, Brazil \\ ${ }^{2}$ Farmanguinhos, Fundação Oswaldo Cruz, Rua Sizenando Nabuco 100, Manguinhos, Rio de Janeiro RJ \\ 21041-250, Brazil \\ ${ }^{3}$ Escola de Química, Universidade Federal do Rio de Janeiro, CT Bloco E, Cidade Universitária, Rio de \\ Janeiro RJ 21949-909, Brazil \\ *raquellopes25@gmail.com
}

Keywords: chiral alcohol, bioreduction ,microorganisms

\section{INTRODUCTION}

Biocatalysis has become an increasingly valuable tool for synthetic chemists. Chiral alcohols with additional functional groups are very important intermediates in the synthesis of enantiomerically pure pharmaceuticals and other important chemicals. ${ }^{1}$ Chiral phenylethanols $(R$ or $S$ ) are an interesting compounds with a number of potential applications, particularly in the drug industry. These alcohols are used as building blocks for the synthesis of bioactive compounds such as pharmaceuticals, agrochemicals and natural products ${ }^{2}$.

In this work, we report the use of 14 microorganisms for the asymmetric reduction of 4-Br-acetophenone.

\section{RESULTS AND DISCUSSION}

In this work, we used 14 microorganisms for the asymmetric reduction of 4-Br-acetophenone (10 yeast strains and 4 filamentous fungi strains) Figure 1. The best results are showed in table 1, some microorganisms such as K.marxianus, Hansenula $\mathrm{sp}$., 3 strains of S.cerevisiae and Phaenerochete sp. showed low conversions (between 3 and 13\%). All the reactions were conduced during 24 hours.

Figure 1. Reduction of 4-Br-Acetophenone

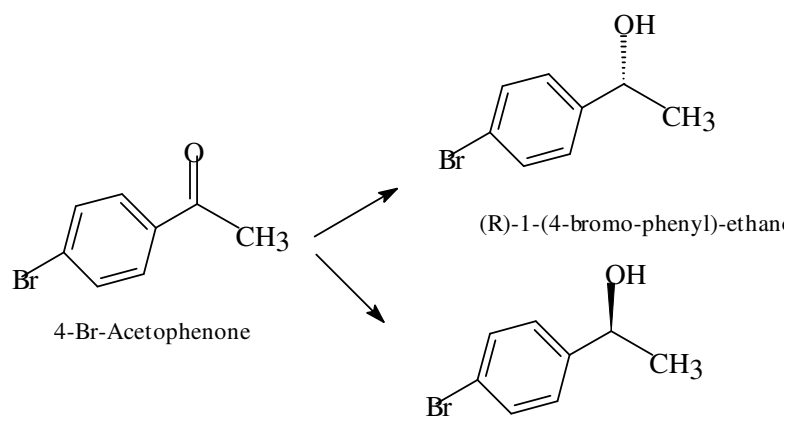

(S)-1-(4-bromo-phenyl)-ethano
Table 1. Bioreduction of 4-Br-acetophenone

\begin{tabular}{|l|c|c|}
\hline Microorganism & Conversion (\%) & e.e. $(\%)^{\star}$ \\
\hline Pichia sp. & 64,5 & $89,8(S)$ \\
\hline G. candidum & 91,9 & $97,4(R)$ \\
\hline A. niger & 98,4 & $100(R)$ \\
\hline M. ramannianus & 100 & $20(S)$ \\
\hline T. harzianum & 98,5 & $98(R)$ \\
\hline R. rubra & 96,13 & $98,8(S)$ \\
\hline R. minuta & 99,36 & $98,2(S)$ \\
\hline Candida sp. & 59,15 & $53,8(R)$ \\
\hline
\end{tabular}

${ }^{*}$ Deterrminated using GC analysis

G.candidum, A.niger and T.harzianum were able to produce the $R$-enantiomer with excellent conversions and e.e. while R.rubra and R.minuta gave the $S$-enantiomer.

We chose 5 microorganisms to monitor the reaction's time, G.candidum, R.rubra, R.minuta, A.niger and T.harzianum. Using G.candidum we found that with 5 hours of reaction the conversion is 95\%. Using R.rubra and R.minuta this conversion is achieved with 10 hours. The filamentous fungi, A.niger and T.harzianum need 24 hours to complete the reaction.

\section{CONCLUSION}

Using microorganisms we are able to produce both enantiomers of 1 -(4-Br-phenyl)-ethanol, in excellent conversions and high enantiomeric excess.

\section{ACKNOWLEDGEMENTS}

Financial support from FINEP, FAPERJ, CAPES and $\mathrm{CNPq}$ - Brazil are acknowledged.

\section{REFERENCES}

${ }^{1}$ Kurbanoglu, E.B., Zilbeyaz, K., Ozdal, M., Taskin, M., Kurbanoglu, N.I. Bioresource Technology 2010, 101, 3825-3829

Zilbeyaz, K., Kurbanoglu, E.B. Bioresource Technology, 2008, 99, 15491552 